\title{
ОСОБЕННОСТИ ФИЗИЧЕСКОГО РАЗВИТИЯ СТУДЕНТОВ ВУЗОВ
}

\author{
(C) Анищенко А.П. ${ }^{2}$, Архангельская А.Н. ${ }^{1}$, Гуревич К.Г. ${ }^{1}$, Дмитриева Е.А. ${ }^{1}$, Игнатов Н.Г. ${ }^{3}$, Рогозная Е.В. ${ }^{3}$
}
${ }^{1}$ Кафедра ЮНЕСКО «Здоровый образ жизни - залог успешного развития», ${ }^{2}$ кафедра физического воспитания и здоровья Московского государственного медико-стоматологического университета имени А.И. Евдокимова, Москва; ${ }^{3}$ Фармацевтический колледж «Новые знания», Москва E-mail: kgurevich@mail.ru

\begin{abstract}
В работе была исследована взаимосвязь физической нагрузки и состояния предожирения среди студентов на примере сравнения учащихся из двух вузов. Первая группа в количестве 102 человек, не занимающихся регулярной физической нагрузкой (таковые составляют основную часть современной молодежи), и вторая - 48 студентов, имеющих первый взрослый разряд. Были определены соотношение талии к бедрам, индекс массы тела (ИМТ), проведено антропометрическое и биоимпедансное исследования, учитывались различия по половому признаку. В результате исследования было выявлено, что наличие физической тренированности является важным фактором в профилактике предожирения.
\end{abstract}

Ключевые слова: факторы риска, предожирение, физическое развитие, студенты, сердечно-сосудистые заболевания.

FEATURES OF PHYSICAL DEVELOPMENT OF UNDERGRADUATES Anishchenko A.P. ${ }^{2}$, Arkhangel'skaya A.N. ${ }^{1}$, Gurevich K.G. ${ }^{1}$, Dmitrieva E.A. ${ }^{1}$, Ignatov N.G. ${ }^{3}$, Rogoznaya E.V. ${ }^{3}$ ${ }^{1}$ Department of UNESCO "Healthy Lifestyle - the Key to Successful Development", ${ }^{2}$ Department of Physical Education and Health of A.I. Evdokimov Moscow State University of Medicine and Dentistry, Moscow;

${ }^{3}$ College of Pharmacy "New knowledge", Moscow

The work describes the interrelationship between students' physical activity and the pre-obese state by comparing students of two different universities. The first group includes 102 people not engaged in regular physical activity (composing the bulk of young men of today) and the second group - 48 students with first senior degree. The waist - hip ratio and body mass index (BMI) were determined and anthropometric and bioimpedance study was conducted taking into account the gender differences. The study found out that the presence of physical fitness is an important factor in the pre-obese prevention.

Keywords: risk factors, pre-obese, physical fitness, students, cardiovascular diseases.

Профилактические мероприятия, направ-ленные на предотвращение действия факторов риска на человека, являются наиболее эффективными в плане укрепления здоровья [10]. В связи с этим фактом выявление таких рисков, как ожирение и недостаточная физическая активность среди молодежи, в т.ч. студентов вузов, представляется наиболее актуальным. Это связано с тем, что студенты являются той активной частью населения, от которой зависит здоровье нации как сейчас, так и в будущем.

Следует особо отметить, что Россия занимает 8-е место в мире по распространенности ожирения среди подростков, а $40 \%$ трудоспособного населения страны имеют избыточный вес или ожирение 2-3-й степени [1]. Данные патологические состояния являются предвестниками таких заболеваний, как сердечно-сосудистые, заболевания бронхолегочной системы и опорно-двигательного аппарата. Высокой степенью риска преждевременной смерти вследствие сердечно-сосудистой патологии обусловливается пристальное внимание к проблемам более раннего выявления факторов риска. Так, метаболические изменения, имеющие место при ожирении, являются ключевыми звеньями в патогенетических механизмах повышения артериального давления, а среди лиц с избыточной массой тела артериальная гипертензия встречается в 5-6 раз чаще, чем у лиц с нормальным весом [9].

Обнаружено, что развитие атеросклероза примерно через 20-25 лет приводит к клинически значимым изменениям гемодинамики, нарушению кровоснабжения органов и тканей, развитию ИБС [3]. Доказано, что избыточная масса тела и ожирение в подростковом возрасте служат предикторами развития артериальной гипертензии, атеросклероза, а образование кальцифицированных отложений («атеро-склеротические полоски») в стенках сосудов является фактором риска развития ИБС. Показано, что наиболее часто развитие избыточной массы тела и ожирения в детско-подростковом возрасте связано не с наследственными, а с приобретенными факторами [5]. Среди последних наибольшее внимание исследователи уделяют питанию и физической активности [6].

Bсе это обусловливает актуальность выявления физического состояния студентов и ранних предикторов ожирения. 
Цель исследования - оценить распространенность избыточного веса и физическое развитие студентов в выборочном исследовании в двух вузах.

\section{МАТЕРИАЛЫ И МЕТОДЫ ИССЛЕДОВАНИЯ}

В исследовании приняли участие две группы студентов, первая из которых - 102 студента МГМСУ (Московский государственный медикостоматологический университет им. А.И. Евдокимова) (60 девушек и 42 юноши) и вторая 48 студентов МГАФК (Московская государственная академия физической культуры) (34 девушки и 14 юношей) в возрасте от 19 до 21 года. Критерием включения в первую группу являлись лица, систематически не занимающиеся физической культурой или спортом, во вторую студенты, имеющие 1-й взрослый разряд, виды спорта были выбраны с учетом направленности физических упражнений, к примеру, на проявления выносливости и общеукрепляющего характера: 25 студентов - бег на средние дистанции, лыжные гонки - 10 студентов и 13 - плавание. Все участники подписали письменное добровольное информированное согласие на обследование. Исследование одобрено этическим комитетом ГБОУ ВПО Московский государственный медико-стоматологический университет им. А.И. Евдокимова Минздрава РФ.

Измерения роста проводились ростомером Диакомс, веса - весами Omron, обхватов талии и бедер - мерной лентой. Точность измерения составила $\pm 0,5 \mathrm{~cm}, \pm 100$ г.

Оценка параметров состава тела осуществлялась по стандартной тетраполярной интегральной методике, с использованием биоимпедансного анализа (БИА) с программным обеспечением АВC-01 «Медасс». Все параметры состава тела, границы интервалов нормальных значений автоматически рассчитываются специализированным программным обеспече-нием.

Процедура БИА выполняется в положении пациента лежа на спине. Одноразовые электроды устанавливаются на кисти и стопе правых конечностей. Длительность измерений параметров импеданса составляет 1-2 секунды, общая длительность исследования - 2-3 минуты. Определяли следующие параметры: индекс массы тела (ИМТ), жировая масса тела (ЖМТ), безжировая (тощая) масса (БМТ), активная клеточная масса (АКМ), процентное содержание жира в теле $(\%$ ЖМТ), процентное содержание активной клеточной массы (\% АКМ), скелетно-мышечная масса (CMM).
Частотный анализ и визуализация результатов проводились в программе MS Excel 2010, Statistics for Windows 10.0. Обсчет проводился с использованием критериев Колмогорова-Смирнова и Манна-Уитни, $\mathrm{t}$-критерия Стьюдента.

\section{РЕЗУЛЬТАТЫ ИССЛЕДОВАНИЯ И ИХ ОБСУЖДЕНИЕ}

Сравнивая физическое состояние студентов, мы обнаружили, что соотношение окружности талии к бедрам у студентов обоих вузов не вышли за пределы нормальных значений (таблица 1). Тот же результат был получен при оценке данного параметра, учитывая гендерные различия. Таким образом, у студентов обеих групп не выявлено признаков абдоминального ожирения, что является одним из факторов риска развития сердечно-сосудистых заболеваний.

Показатели ИМТ у студентов (девушек и юношей) МГМСУ также были в пределах нормы. То же отмечается и для девушек МГАФК. Однако у юношей МГАФК ИМТ выше нормы $(27,7$ кг/м²). Между тем, как показывают результаты биоимпедансного анализа, данное увеличение происходит за счет мышечной, а не жировой массы [7]. Таким образом, следует учитывать данную особенность при использовании методов антропометрии для оценки физического развития юношей-спортсменов. То есть импедансный метод является взаимодополняющим к расчету ИМТ для лиц, занимающихся интенсивными физическими нагрузками и позволяет исключить погрешности в диагностировании избыточной массы тела при отсутствии фактического избытка жировой ткани [8].

Следует отметить, что в целом у студентов МГАФК содержание жировой ткани ниже, чем у студентов МГМСУ, хотя в обеих группах данный показатель не выходит за рамки нормативных значений. Студенты МГАФК по сравнению с учащимися МГМСУ характеризуются более высоким уровнем развития активной и скелетной массы, у них выше уровень основного обмена [2]. Имеются гендерные отличия у обучающихся в одном вузе, что подчеркивает необходимость изучения факторов риска с учетом половой принадлежности. Уровень жировой массы у юношей выше, чем у девушек МГМСУ. Также отмечаются статистически значимые различия по показателям тощей массы, активной клеточной и скелетно-мышечной масс; у юношей они выше по сравнению с девушками. Данные различия отмечены у студентов обоих вузов.

С нашей точки зрения, выявленные различия между студентами в первую очередь связаны с наличием физической натренированности и отсутствием таковой у другой группы студентов. 
Результаты антропометрического и биоимпедансного исследований при $\mathrm{p}<0,05$

\begin{tabular}{|c|c|c|c|c|c|c|}
\hline \multirow{2}{*}{ Показатели } & \multicolumn{2}{|c|}{ Студенты МГМСУ } & \multicolumn{2}{|c|}{ Студенты МГАФК } & $\begin{array}{l}\text { Студенты } \\
\text { МГМСУ }\end{array}$ & $\begin{array}{c}\text { Студенты } \\
\text { МГАФК }\end{array}$ \\
\hline & Девушки & Юноши & Девушки & Юноши & $\begin{array}{c}\text { Девушки и } \\
\text { юноши }\end{array}$ & $\begin{array}{l}\text { Девушки } \\
\text { и юноши }\end{array}$ \\
\hline Вес, кг & $58,3 \pm 9,2$ & $74,7 \pm 10,4^{*}$ & $63,3 \pm 13,4$ & $83,1 \pm 0,01 *$ & $60,5 \pm 11,4$ & $75,4 \pm 10,2 \#$ \\
\hline Рост, см & $166,0 \pm 5,4^{*}$ & $180,1 \pm 6,9$ & $\begin{array}{c}168,4 \pm 10 \\
1\end{array}$ & $173,0 \pm 0,01$ & $167,1 \pm 7,8$ & $179,5 \pm 6,9 \#$ \\
\hline Талия/бедра & $0,74 \pm 0,06$ & $0,80 \pm 0,19$ & $0,81 \pm 0,04$ & $0,84 \pm 0.01$ & $1,2 \pm 3,3 \#$ & $0,8 \pm 0,2$ \\
\hline ИМТ, кг $/ \mathrm{M}^{2}$ & $21,2 \pm 3,2$ & $23 \pm 2,8$ & $22,1 \pm 3,2$ & $27,7 \pm 0,01^{*}$ & $21,6 \pm 3,2$ & $23,4 \pm 3,0$ \\
\hline Жировая масса, кг & $16,1 \pm 6,9$ & $20,9 \pm 0,01^{*}$ & $14,7 \pm 6,2$ & $14,3 \pm 6,4$ & $17,8 \pm 6,4 \#$ & $14,3 \pm 6,5$ \\
\hline Тощая масса, кг & $43,6 \pm 4,5$ & $60,4 \pm 7,0^{*}$ & $45,3 \pm 12,5$ & $62,1 \pm 0,01^{*}$ & $44,3 \pm 8,9$ & $60,6 \pm 6,7 \#$ \\
\hline $\begin{array}{c}\text { Активная клеточная } \\
\text { масса, кг }\end{array}$ & $24,2 \pm 3,3$ & $36,1 \pm 3,4^{*}$ & $27,6 \pm 7,2$ & $39,6 \pm 0,01 *$ & $25,7 \pm 5,6$ & $36,3 \pm 3,4 \#$ \\
\hline $\begin{array}{c}\text { Скелетно-мышечная } \\
\text { масса, кг } \\
\end{array}$ & $21,6 \pm 2,8$ & $32,8 \pm 3,9^{*}$ & $24,4 \pm 6,6$ & $32,9 \pm 0,01 *$ & $22,8 \pm 4,9$ & $32,8 \pm 3,8 \#$ \\
\hline $\begin{array}{c}\text { Основной обмен, } \\
\text { ккал/сут. }\end{array}$ & $\begin{array}{l}1380,3 \\
\pm 104,7\end{array}$ & $\begin{array}{c}1754,6 \\
\pm 107,4^{*}\end{array}$ & $\begin{array}{l}1490,1 \\
\pm 229,7\end{array}$ & $\begin{array}{l}1867,1 \\
\pm 0,01^{*}\end{array}$ & $\begin{array}{l}1426,8 \\
\pm 176,8\end{array}$ & $\begin{array}{c}1764,2 \\
\pm 107,4 \#\end{array}$ \\
\hline
\end{tabular}

Примечание: * - отмечены статистически значимые отличия юношей от девушек, \# - отмечены статистически значимые отличия у студентов МГАФК от студентов МГМСУ.

Обучение во МГАФК предполагает высокий уровень тренированности, тогда как для студентов МГМСУ данное требование не является обязательным.

Найденный нами более высокий уровень содержания жировой ткани у студентов-медиков хотя и не выходит за рамки нормативных значений, однако может рассматриваться как предвестник развития ожирения в будущем [4]. Таким образом, можно предположить, что низкая повседневная активность слушателей МГМСУ является фактором риска развития хронических неинфекционных заболеваний в будущем.

На основении проведенных исследований можно сделать следующие выводы:

1. Использование антропометрических измерений оказалось недостаточно информативным для выявления избытка жировой ткани у лиц, занимающихся спортом. Более предпочтительным методом является БИА.

2. Студенты МГМСУ по сравнению со студентами МГАФК имеют более низкий уровень развития мышечной ткани и более высокую степень развития жировой, что на фоне более низкой физической активности можно рассматривать как предикторы ожирения.

\section{ЛИТЕРАТУРА}

1. Глани С. Медико-биологическая статистика. - М. : Практика, 1998. - 459 с.

2. Гуревич К.Г., Гачегов М.А., Маев И.В. Основы здорового образа жизни. - М. - Пермь, 2011. $106 \mathrm{c}$.
3. Кобалава Ж.Д., Котовская Ю.В., Моисеев В.С. Артериальная гипертония // Ключи к диагностике и лечению. (Серия «Библиотека врача-специалиста»). - М. : ГЭОТАР-Медиа, 2009. - 864 с.

4. Матосян К.А., Оранская А.Н., Пустовалов Д.А., Черепкова Е.В., Скотникова Ю.В., Бурдюкова Е.В., Анищенко А.П. Гуревич К.Г., Ханферьян P.A. Особенности количественного состава жировой ткани в организме в пубертантном и постпубертатном возрасте с учетом возраста, пола, уровня физической активности и характера питания // Вопросы питания. - 2015. - Т. 84, № 5. - С. 90-96.

5. Ожирение и избыточный вес. ВОЗ. [Электронный pecypc] // ВОЗ. - 2015. - Информационный бюллетень № 311. Режим доступа: http://www.who.int/mediacentre/factsheets/fs311/ru/, свободный (06.03.2016).

6. Ожирение: этиология, патогенез, клинические аспекты / Под ред. И.И. Дедов, Г.А. Мельниченко М. : Медицинское информационное агентство, 2006. $-456 \mathrm{c}$.

7. Руднев С.В., Соболева Н.П., Николаев Д.В. Биоимпедансное исследование состава тела населения России. - М. : РИО ЦНИИОИЗ, 2014. $493 \mathrm{c}$.

8. Физическая активность. ВОЗ. [Электронный pecypc] // ВОЗ. - 2014. - Информационный бюллетень № 384 . Режим доступа: http://www.who.int/mediacentre/factsheets/fs385/ru/, свободный (06.03.2016).

9. Чазова И.Е., Мычка В.Б. Метаболический синдром и артериальная гипертония // Артериальная гипертензия. -2002 . № 1. - С. 7-10.

10. Ющук Н.Д., Маев И.В., Гуревич К.Г. Здоровый образ жизни и профилактика заболеваний. - М. : Практика, 2015. - 412 с. 